\title{
Exercising Bioengineered Skeletal Muscle In Vitro: Biopsy to Bioreactor
}

\author{
Daniel C. Turner, Andreas M. Kasper, Robert A. Seaborne, Alexander D. Brown, \\ Graeme L. Close, Mark Murphy, Claire E. Stewart, Neil R. W. Martin, \\ and Adam P. Sharples*
}

\begin{abstract}
The bioengineering of skeletal muscle tissue in-vitro has enabled researchers to more closely mimic the in-vivo skeletal muscle niche. The three-dimensional (3-D) structure of the tissue engineered systems employed to date enable the generation of highly aligned and differentiated myofibers within a representative biological matrix. The use of electrical stimulation to model concentric contraction, via innervation of the myofibers, and the use of mechanical loading to model passive lengthening or stretch has begun to provide a manipulable environment to investigate the cellular and molecular responses following exercise mimicking stimuli in-vitro. Currently available bioreactor systems allow either electrical stimulation or mechanical loading to be utilized at any given time. In the present manuscript, we describe in detail the methodological procedures to create 3-D bioengineered skeletal muscle using both cell lines and/or primary human muscle derived cells from a tissue biopsy, through to modeling exercising stimuli using a bioreactor that can provide both electrical stimulation and mechanical loading simultaneously within the same in-vitro system.
\end{abstract}

Key words Skeletal muscle, Tissue engineering, Bioengineering, Myoblasts, Satellite cells, Exercise, Biological scaffolds

Daniel C. Turner and Andreas M. Kasper contributed equally to this work.

*Adam P. Sharples is the senior/corresponding author.

1 Introduction

Exercising differentiated multinucleated skeletal muscle cells (myotubes/ fibers) in monolayer cultures by means of electrical stimulation $[1,2]$ and mechanical stretch $[3,4]$ has partially mimicked responses following resistance $[4,5]$ and endurance $[6,7]$ exercise in-vivo. Following pioneering work by Vandenburgh and colleagues three decades ago, culturing in 3-dimensional (3-D) microenvironments may however be considered a more representative model of the in-vivo skeletal muscle niche $[8,9]$ and with continuing progression, may predominate as an in-vitro tool for investigating the underlying mechanisms of exercise adaptation. Indeed, 3-D tissue engineered skeletal muscle models display highly aligned and differentiated myotubes [10,11], permitting measures of muscle function [12-16] that are not entirely possible with monolayer cultures where swirling myotube formation results in non-uniaxial force generation. Furthermore, embedding skeletal muscle cells within representative extracellular matrices (e.g. collagen, laminin, fibrin) and allowing their differentiation into myotubes increases the amount of time the myotubes can be kept in culture. Where in monolayer, myotubes may begin to detach, especially following spontaneous contraction due to poorer matrix attachment [10]. The use of self-assembling fibrin "myooids" may also prove advantageous for 3-D skeletal muscle tissue engineering given that the cells can easily proliferate and become confluent prior to differentiation versus the use of a stiffer matrix such as collagen where proliferation maybe inhibited, and therefore fibrin "myooids" usually require lower seeding densities. This is particularly useful if trying to generate bioengineered muscle using limited primary muscle derived cells that eventually senesce. Fibrin myooids also provide superior functionality, such as force production vs. other biological scaffolds and can allow efficient gene transfection [14, 15, 17-20]. Collectively, the advantages of these engineered systems may help delineate the underlying mechanisms of physiological adaptation in response to exercise mimicking stimuli in-vitro. Once fully formed into a cylindrical like muscle, constructs undergo electrical $[5,12-15,17,21]$ or mechanical $[22,23]$ stimulation which can mimic shortening andlengthening contraction of skeletal muscle, respectively. Typically however, only one of these stimulation modes is utilized at once. Therefore, a system that can perform both of these functions simultaneously would be advantageous. Furthermore, delivering an electrical input during the lengthening portion of the movement would also provide a more relevant contraction vs. simply a passive lengthening/stretch, as muscle activity/tension is required to control an eccentric contraction in-vivo. Here, we describe the methodological procedures for creating 3-D bioengineered skeletal muscle constructs, using human skeletal muscle derived cells (SkMDC's) and/or the C2C12 myoblast cell line [24, 25] within a fibrin matrix. We further describe how to undertake stimulatory regimes using a commercially available (with customizations) bioreactor system permitting simultaneous electrical and mechanical stimulation. 


\section{Materials}

\subsection{Skeletal Muscle Biopsy Procedure}

1. Disposable sterile scalpel.

2. Sterile biopsy instrument: Monopty® disposable core biopsy instrument (e.g., CR Bard, Crawley, UK) or a conchotome biopsy tool (e.g., Gebru“der Zepf Medizintechnik, Dürbheim, DEU) (see Note 1).

3. $6 \times 75 \mathrm{~mm}$ steri-strips.

4. $7.5 \mathrm{~cm} \times 5 \mathrm{~cm}$ sterile wound dressing plaster with transparent waterproof film.

$5.1 .5 \mathrm{ml} 0.5 \%$ bupivacaine hydrochloride prescribed by a designated physician/medical doctor.

6. Sterile wound cleansing and dressing pack (including swabs, sheet and tray).

7. Fine intramuscular injection needle.

8. Sterile $5 \mathrm{ml}$ syringe.

9. Hydrex surgical scrub (e.g., Ecolabఠ, UK).

10. Sterile surgical gloves.

11. Disposable hospital razor.

12. $1.5 \mathrm{ml}$ transfer medium: Ham's F-10 medium that includes $1 \mathrm{mM}$ L-glutamine, $0.1 \%$ heat inactivated fetal bovine serum (hiFBS) (see Note 2), $0.1 \%$ heat inactivated new born calf serum (hiNBCS) (see Note 2), $100 \mathrm{U} / \mathrm{ml}$ penicillin, $100 \mu \mathrm{g} / \mathrm{ml}$ streptomycin, $2.5 \mu \mathrm{g} / \mathrm{ml}$ amphotericin B. Stored and used at $4{ }^{\circ} \mathrm{C}$.

13. Sterile $2 \mathrm{ml}$ Eppendorf tube containing transfer medium submerged in ice.

\subsection{Human Primary Cell Isolation}

1. Growth medium: Ham's F-10 medium that includes $1 \mathrm{mM}$ Lglutamine, $10 \%$ hiFBS, $10 \%$ hiNBCS, supplemented with an additional $2 \mathrm{mM}$ L-glutamine, $100 \mathrm{U} / \mathrm{ml}$ penicillin, $100 \mu \mathrm{g} / \mathrm{ml}$ streptomycin, $2.5 \mu \mathrm{g} / \mathrm{ml}$ amphotericin B. Stored at $4^{\circ} \mathrm{C}$.

2. Horse serum (HS) (to neutralize trypsin).

3. $0.5 \%$ Trypsin- $0.2 \%$ EDTA.

4. 0.01Mphosphate buffered saline (1x) (PBS): PBS dissolved in distilled water $\left(\mathrm{dH}_{2} 0\right), 100 \mathrm{U} / \mathrm{ml}$ penicillin, $100 \mu \mathrm{g} / \mathrm{ml}$ streptomycin, $2.5 \mu \mathrm{g} / \mathrm{ml}$ amphotericin B (see Note 1). Stored at room temperature.

5. 2 x sterile scalpels: either blades (see Note 1) or disposable sterile scalpel.

6. Magnetic stirring bar $(6 \times 35 \mathrm{~mm})$ with platform (preheated to $\left.37^{\circ} \mathrm{C}\right)$ (see Note 1 ).

7. Disposable sterile petri dish (100 $\mathrm{mm}$ diameter).

8. Sterile $100 \mathrm{ml}$ specimen container.

9. $2 \mathrm{mg} / \mathrm{ml}$ gelatin from porcine skin (Type A; Sigma-Aldrich, G2500) dissolved in distilled water $\left(\mathrm{dH}_{2} \mathrm{O}\right)$ (see Notes 1 and 3).

\subsection{Cryopreservation of Cells}

1. Growth medium for primary human cell culture: Ham's F-10 medium that includes $1 \mathrm{mM}$ L-glutamine, $10 \%$ hiFBS, $10 \%$ hiNBCS, supplemented with an additional $2 \mathrm{mM}$ L-glutamine and $100 \mathrm{U} / \mathrm{ml}$ penicillin, $100 \mu \mathrm{g} / \mathrm{ml}$ streptomycin, $2.5 \mu \mathrm{g} / \mathrm{ml}$ amphotericin B. Stored at $4^{\circ} \mathrm{C}$.

2. Growth medium for C2C12 cell culture: Dulbecco's modified Eagle's medium (DMEM) that includes 4 mM L-glutamine, 10\% hiFBS, 10\% hiNBCS, supplemented with an additional $2 \mathrm{mML}$-glutamine, $100 \mathrm{U} / \mathrm{ml}$ penicillin, $100 \mu \mathrm{g} / \mathrm{ml}$ streptomycin. Stored at $4^{\circ} \mathrm{C}$.

3. Cell culture grade dimethyl sulfoxide (DMSO).

4. Cryopreservation freezer container (e.g. "Mr. frosty").

5. PBS (see Note 1). Stored at room temperature.

6. $0.5 \%$ Trypsin- $0.2 \%$ EDTA.

\subsection{Resuscitation of Cryopreserved Cells}

1. $2 \mathrm{mg} / \mathrm{ml}$ gelatin (see Note 3). Stored at room temperature.

2. Growth medium for primary human cell culture: Ham's F-10 medium that includes $1 \mathrm{mM}$ L-glutamine, $10 \%$ hiFBS, $10 \%$ hiNBCS, supplemented with an additional $2 \mathrm{mM}$ L-glutamine and $100 \mathrm{U} / \mathrm{ml}$ penicillin, $100 \mu \mathrm{g} / \mathrm{ml}$ streptomycin, $2.5 \mu \mathrm{g} / \mathrm{ml}$ amphotericin B. Stored at $4{ }^{\circ} \mathrm{C}$. 
3. Growth medium for $\mathrm{C} 2 \mathrm{C} 12$ cell culture: DMEM that includes $4 \mathrm{mM}$-glutamine, $10 \%$ hiFBS, $10 \%$ hiNBCS, supplemented with an additional $2 \mathrm{mML}$-glutamine and $100 \mathrm{U} / \mathrm{ml}$ penicillin, $100 \mu \mathrm{g} / \mathrm{ml}$ streptomycin. Stored at $4^{\circ} \mathrm{C}$.

\subsection{3-D Culture Dishes}

1. Easy-Grip $35 \mathrm{~mm}$ dishes (BD Falcon $\circledast$ ).

2. Sylgard® 184 Elastomer kit (Dow Corning, MI, USA) (see Note 4).

3. $0.15 \mathrm{~mm}$ minutien pins (see Note 5).

4. Silk suture thread (2.0) (see Note 6).

5. $70 \%$ ethanol.

6. 0.01 M PBS (see Note 1). Stored at room temperature.

\subsection{Fibrin Skeletal Muscle Constructs}

1. Fibrinogen from Bovine Plasma (Sigma-Aldrich, F8630): Dissolve fibrinogen (stored at $-20{ }^{\circ} \mathrm{C}$ ) at 20 $\mathrm{mg} / \mathrm{ml}$ in preheated $\left(37^{\circ} \mathrm{C}\right)$ Ham's F12-K medium and incubate at $37^{\circ} \mathrm{C}$ for $2-3 \mathrm{~h}$, swirling every $30 \mathrm{~min}$ (see Note 7). Vacuum filter $(0.22 \mu \mathrm{m}$; see Note 8$)$, aliquot and store at $-20^{\circ} \mathrm{C}$ (see Note 9 ).

2. Thrombin from Bovine Plasma (Sigma-Aldrich, T4648): Dissolve thrombin at $200 \mathrm{U} / \mathrm{ml}$ in $5 \mathrm{ml}$ of high glucose (4.5 g/l) DMEM (see Note 10). Sterile filter $(0.22 \mu \mathrm{m})$, aliquot and store at $-20^{\circ} \mathrm{C}$ (see Note 9 ).

3. Aprotinin from Bovine Lung (Sigma-Aldrich, A3428-10MG): Dissolve total $10 \mathrm{mg}$ aprotinin in $1 \mathrm{ml}$ of distilled water $\left(\mathrm{dH}_{2} 0\right)$ to ensure a stock concentration of $10 \mathrm{mg} / \mathrm{ml}$. Sterile filter $(0.22 \mu \mathrm{m})$, aliquot and store at $20^{\circ} \mathrm{C}$.

4. 6-Aminocaproic Acid (Sigma-Aldrich, A7824): Dissolve 6-aminocaproic acid at $50 \mathrm{mg} / \mathrm{ml}$ in distilled water $\left(\mathrm{dH}_{2} 0\right)$. Sterile filter $(0.22 \mu \mathrm{m})$, aliquot and store at $4^{\circ} \mathrm{C}$ (see Note 11 ).

5. L-Ascorbic Acid (Sigma-Aldrich, A4403): Dissolve total $100 \mathrm{mg}$ L-ascorbic acid in $11.36 \mathrm{ml}$ of high glucose (4.5 g/l) DMEM to ensure a stock concentration of $50 \mathrm{mM}$. Sterile filter

$(0.22 \mu \mathrm{m})$, aliquot and store at $4^{\circ} \mathrm{C}$ (see Note 12$)$.

6. L-Proline (Sigma-Aldrich, P8865): Dissolve $100 \mathrm{mg}$ L-proline in $17.37 \mathrm{ml} 0.01 \mathrm{M}$ PBS (see Note 1) to ensure a stock concentration of $50 \mathrm{mM}$. Sterile filter $(0.22 \mu \mathrm{m})$, aliquot and store at $4{ }^{\circ} \mathrm{C}$ (see Note 12 ).

7. Genipin (Sigma-Aldrich, G4796): Dissolve genipin at $10 \mathrm{mg} / \mathrm{ml}$ in DMSO (see Note 13). Sterile filter $(0.22 \mu \mathrm{m})$, aliquot and store at $-20^{\circ} \mathrm{C}$.

8. Growth medium: High glucose (4.5 g/l) DMEM that includes $4 \mathrm{mM}$ L-glutamine, $10 \%$ hiFBS, $10 \%$ hiNBCS, supplemented with an additional $2 \mathrm{mM}$ L-glutamine, $100 \mathrm{U} / \mathrm{ml}$ penicillin, $100 \mu \mathrm{g} / \mathrm{ml}$ streptomycin (see Note 14), $0.5 \mathrm{mg} / \mathrm{ml}$ 6-aminocaproic acid, $50 \mu \mathrm{M}$ L-ascorbic acid, $50 \mu \mathrm{M}$ L-proline (see Note 12). Stored at $4^{\circ} \mathrm{C}$.

9. Differentiation medium: High glucose (4.5 g/l) DMEM that includes $4 \mathrm{mM}$ L-glutamine, $2 \% \mathrm{HS}$, supplemented with an additional $2 \mathrm{mM}$ L-glutamine, $100 \mathrm{U} / \mathrm{ml}$ penicillin, $100 \mu \mathrm{g} / \mathrm{ml}$ streptomycin (see Note 14), $1 \mathrm{mg} / \mathrm{ml}$ 6-aminocaproic acid, $50 \mu \mathrm{M}$ L-ascorbic acid, $50 \mu \mathrm{M}$ L-proline (see Note 12 ). Stored at $4{ }^{\circ} \mathrm{C}$.

10. Maintenance medium: High glucose (4.5 g/l) DMEM that includes $4 \mathrm{mM}$ L-glutamine, $3.5 \% \mathrm{hiFB}, 3.5 \%$ hiNBCS, supplemented with an additional $2 \mathrm{mM}$ L-glutamine, $100 \mathrm{U} / \mathrm{ml}$ penicillin, $100 \mu \mathrm{g} / \mathrm{ml}$ streptomycin (see Note 14), $1 \mathrm{mg} / \mathrm{ml}$ 6-aminocaproic acid, $50 \mu \mathrm{M}$ L-ascorbic acid, $50 \mu \mathrm{M}$ L-proline (see Note 12). Stored at $4^{\circ} \mathrm{C}$.

11. Sylgard coated dishes (see Note 4).

2.7 TC-3 Bioreactor System (Ebers Medical Technology, ESP) (See Note 15)

1. Control module.

2. 3-D bioreactor cell culture chamber(s) including parts such as clamps and screws (see Note 1).

3. Laptop/desktop with controlling software.

4. Peristaltic pump/perfusion box.

5. Electrical Stimulation: Electrical stimulation module, output box, electrode anode/cathode splitter, platinum/pure iridium or stainless steel electrodes (see Note 1).

6. Mechanical Stimulation: Mechanical stimulation box.

2.8 From the Culture Dish to the Bioreactor

1. TC-3 Bioreactor chamber(s) (e.g. Ebers Medical Technology,ESP). 
2. $2 \mathrm{x}$ sets of angled surgical tweezers (see Notes 1 and 16).

3. Maintenance medium: High glucose (4.5 g/l) DMEM that includes $4 \mathrm{mM} \mathrm{L-glutamine,} 3.5 \% \mathrm{hiFB}, 3.5 \%$ hiNBCS, supplemented with an additional $2 \mathrm{mM}$ L-glutamine, $100 \mathrm{U} / \mathrm{ml}$ penicillin, $100 \mu \mathrm{g} / \mathrm{ml}$ streptomycin (see Note 14), $1 \mathrm{mg} / \mathrm{ml}$ 6-aminocaproic acid, $50 \mu \mathrm{M}$ L-ascorbic acid, $50 \mu \mathrm{M}$ L-proline

(see Note 12). Stored at $4^{\circ} \mathrm{C}$.

\section{Methods}

All procedures must be conducted under fully aseptic conditions. Following relevant ethical approval and informed consent of the participants, the skeletal muscle biopsy procedure must be undertaken by fully trained and insured individuals, usually a physician/ clinician. A full medical screen by the physician of the participant is also required and the participants GP/family doctor should be informed. When preparing all biopsy equipment/contents, it is essential that direct contact is only made to the exterior packaging. If transported, the muscle tissue must be immersed in chilled $\left(4^{\circ} \mathrm{C}\right)$ transfer medium and transported to a sterile Class 2 cell culture hood/microbiological safety cabinet (BSC) as soon as possible to undergo subsequent cell isolation procedures. Furthermore, the storage and disposal of any tissue and waste should be in accordance to the relevant legislation, (e.g. in the UK, the Human Tissue Act (2004), and Control of Substances Hazardous to Health (2002) regulations, respectively).

\subsection{Skeletal Muscle Biopsy Procedure}

1. Ensure participant is laying in a supine position before shaving the desired area (in this case, the skin above the belly of the vastus lateralis) with a disposable razor.

2. Empty the wound dressing pack onto a sterile trolley, avoiding contact with the inner dressing. The biopsy instrument, syringe, needle gauge, scalpel, suture pack and plaster can now be opened and placed on the sheet of the sterile dressing pack (Fig. 1).

3. Pour the surgical scrub into the wound dressing tray and unpackage the Marcain and sterile surgical gloves.

1

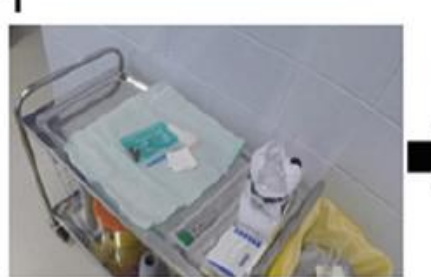

6

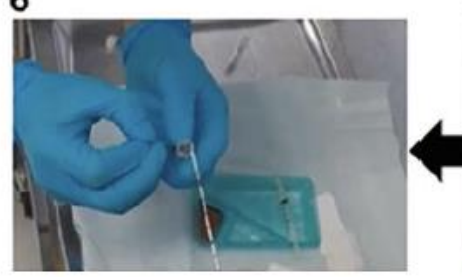

2

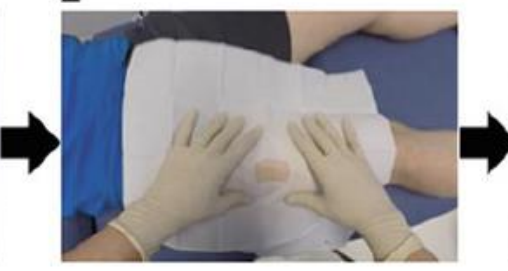

5

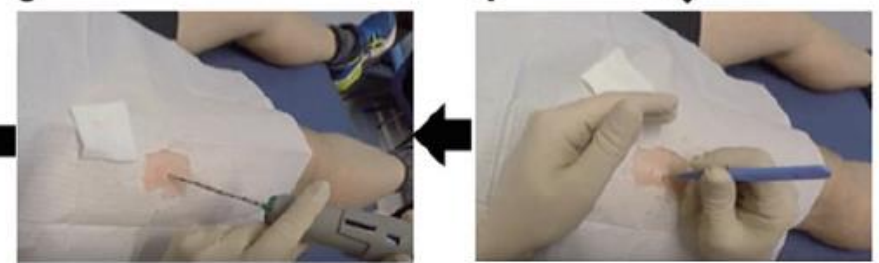

Fig. 1 Depicts (1) removing all packaging of relevant equipment and placing onto a sterile working trolley. (2) Wound dressing sheet placed over the subjects leg with the skin of the biopsy area exposed. (3) Injection of anaesthetic into the deep fascia. (4) Incision of scalpel through the superficial layers and epimysium of the muscle. (5) Insertion of the biopsy needle to obtain muscle tissue which is then (6) transferred to the Eppendorf tube containing transfer medium $\left(4^{\circ} \mathrm{C}\right)$ and submerged in ice

4. Put on the sterile surgical gloves, ensuring the exterior does not make contact with the skin or objects which are non-sterile.

5. Using wound dressing swabs and surgical scrub, wipe the desired biopsy area in order to cleanse the skin. Place the wound dressing sheet/fenestrated drape over the participants leg with the skin of the desired biopsy area exposed (Fig. 1).

6. Assemble the sterile needle and syringe and withdraw the prescribed amount of anesthetic $(1.5 \mathrm{ml})$ ensuring no air bubbles are present. Insert the needle subcutaneously and inject $~ 50 \%$ 
( $\sim 0.75 \mathrm{ml})$ of until there are signs of peau d'orange (skin resembles orange peel). Insert the needle a little deeper and inject the remaining anesthetic into the deep fascia (Fig. 1) (see Note 17). To ensure the anesthetic has taken effect (usually 1-2 min post administration), gently apply pressure to the biopsy area with a scalpel (without incision) and ask the participant to verbally confirm a lack of feeling together with numbness.

7. Once anesthetized, using the scalpel, make an incision through the superficial layers and epimysium of the muscle. The tip of the biopsy gun may now be inserted into the wound and muscle tissue may be obtained (Fig. 1). Alternatively, when obtaining muscle tissue using a conchotome instrument, it is important to ensure an incision is made to the fascia to avoid additional pressure and discomfort. You may then insert and rotate $\left(90^{\circ}\right)$ the instrument to cut and extract the muscle tissue [26] (see Note 18).

8. Using a sterile scalpel, scrape the muscle tissue into a sterile tube containing transfer medium $\left(4^{\circ} \mathrm{C}\right)$ and submerge in ice (Fig. 1).

9. Following 2-3 min (needle biopsy instrument) or 5-10 $\mathrm{min}$ (conchotome) of applied pressure to stop the bleeding, clean the area using surgical scrub prior to dressing the wound. Once dry, place the steri-strips both horizontally and diagonally across the wound. Finally, cover the wound with a large sterile waterproof dressing. Instruct the participant that he/she should keep the dressing on for 1-2 weeks and should refrain from swimming, especially in open water or in public pools, alongside covering with waterproof film when showering to further reduce risk of infection.

10. The biopsy sample can now be transferred on ice to the class 2 cell culture hood/BSC for subsequent primary cell isolation.

\subsection{Human Primary Cell Isolation}

1. Using a modified version of methods previously used [27], empty the contents of the sterile tube into an irradiated sterile petri dish and pipette off the transfer medium (see Note 19). The biopsy sample should then undergo 3 x PBS (preheated to $37^{\circ} \mathrm{C}$ ) washes and any visible connective and adipose tissue must be removed using a sterile scalpel.

2. Add $5 \mathrm{ml}$ of trypsin-EDTA (preheated to $37^{\circ} \mathrm{C}$ ) to the sample and mince using two sterile scalpels for at least $1 \mathrm{~min}$.

3. Add the trypsin-EDTA solution and a sterile magnetic stirrer (see Note 1) to a sterile $100 \mathrm{ml}$ specimen container and place on a heated magnetic stirring platform at $37^{\circ} \mathrm{C}$ for $10 \mathrm{~min}$. Alternatively, place the sterile specimen container on a magnetic stirring platform without heating in an oven/incubator set at $37^{\circ} \mathrm{C}$ for 10 $\min$.

4. While the sample is digesting, add $1 \mathrm{ml}$ of preheated $\left(37^{\circ} \mathrm{C}\right) \mathrm{HS}$ into a separate $15 \mathrm{ml}$ sterile tube. This will neutralize the trypsin in step 5.

5. Following 10 mins of heated stirring, remove the trypsin-EDTA solution/supernatant via hand pipetting (see Note 19) and add to the pre-prepared HS as in step 4, leaving the remaining dissected tissue sample in the petri dish. Place the $15 \mathrm{ml}$ tube containing the supernatant and $\mathrm{HS}$ into an incubator $\left(37^{\circ} \mathrm{C}\right)$.

6. Add another $5 \mathrm{ml}$ of trypsin-EDTA to the remaining dissected tissue and dissect/mince again for at least 1 min. Place the tissue back on the heated stirrer and repeat as in step 3.

7. Once stirred, remove the $5 \mathrm{ml}$ trypsin-EDTA and add to HS/ trypsin-EDTA mixture $(6 \mathrm{ml})$ already derived as in step 5, yielding approximately $11 \mathrm{ml}$ of solution (1 $\mathrm{ml} \mathrm{HS}$ and $2 \times 5 \mathrm{ml}$ trypsin-EDTA/supernatant) within the $15 \mathrm{ml}$ tube.

8. To isolate the cells from the supernatant, centrifuge the $15 \mathrm{ml}$ tube at $340 \mathrm{xg}$ for $5 \mathrm{~min}$.

9. While in the centrifuge, the remaining tissue in the petri dish should be plated on a pregelatinized T25 flask with $7.5 \mathrm{ml}$ of growth medium to derive any remaining cells using an explant technique from the post enzymatically digested tissue derived above (see Note 20).

10. Following centrifugation after step 8 above, a cell pellet should be visible at the bottom of the tube.

Carefully remove the top $2.5 \mathrm{ml}$ of supernatant (see Note 19).

11. Resuspend the next $5 \mathrm{ml}$ of supernatant in $5 \mathrm{ml}$ of fresh growth medium in a separate pregelatinized T25 to enable the culture of the isolated cells (see Note 20).

12. Finally, resuspend the remaining bottom $2.5 \mathrm{ml}$ of supernatant (including cell pellet) in $7.5 \mathrm{ml}$ of fresh growth medium in a separate pregelatinized T25 to enable the culture of cells derived from the above enzymatic digestion (see Note 20).

13. Allow cells to culture over the ensuing 5. days without disturbing or removing from the incubator. Additional growth medium should only be added at 7 days to enable full adherence and maintain any cell 
secreted factors. Cells should then be monitored frequently to assess cell growth and to avoid cells becoming over-confluent and any unwanted cell fusion. Once $80 \%$ confluent, cells can be split into larger T75 flasks to generate enough cells for the creation of fibrin bioengineered skeletal muscle (see Note 21) dependent on the experimental design and the number of fibrin gels required (see Sect. 3.6). Cells can also be cryopreserved for later use (see Sect. 3.3 below).

\subsection{Cryopreservation of Cells}

1. Preheat growth medium (primary or $\mathrm{C} 2 \mathrm{C} 12$ culture medium), PBS, and trypsin-EDTA to $37^{\circ} \mathrm{C}$.

2. Once PBS is heated, wash the cells $2-3$ times, aspirating/ removing PBS after each wash.

3. Add $1 \mathrm{ml}$ of trypsin-EDTA and incubate at $37^{\circ} \mathrm{C}$ for $5 \mathrm{~min}$. Gently agitate the cells and visualize down an inverted phase contrast microscope to ensure they have all detached from the plastic culture flask surface.

4. Add $4 \mathrm{ml}$ of growth medium to neutralize the trypsin-EDTA solution. Pool cell solution from all flasks of the same participant (primary) or passage number (C2C12) and add to a sterile tube (e.g., $15 \mathrm{ml}$ or $50 \mathrm{ml}$ ). Homogenize cell solution slowly (see Note 22).

5. Count cells using preferred method (i.e. manually using a hemocytometer or electronically using an automated cell counter) and dilute solution to $1 \times 10^{\circ}$ cells $/ \mathrm{ml}$ using fresh growth medium.

6. Pool solution into a sterile $100 \mathrm{ml}$ specimen container or $50 \mathrm{ml}$ tube and add 10\% DMSO (see Note 23) to prevent formation of ice crystals.

7. Once resuspended, pipette $2 \mathrm{ml}$ of cell solution per prelabeled cryovial (name, cell type, passage number, cell density, and date) and place into a cryopreservation freezer container (i.e. "Mr frosty") filled with isopropanol to ensure a gradual $\left(\sim 1^{\circ} \mathrm{C} / \mathrm{min}\right)$ decrease in temperature, further reducing the likelihood of ice crystal formation.

8. Place the cells into a $-80^{\circ} \mathrm{C}$ freezer for $24 \mathrm{~h}$ prior to storing cells in liquid nitrogen.

\subsection{Resuscitation of Cryopreserved Cells}

1. Preheat growth medium to $37^{\circ} \mathrm{C}$ and gelatinize a T25 (primary cells) or $\mathrm{T} 75(\mathrm{C} 2 \mathrm{C} 12$ cells) flask per vial. 2. Remove the cryovial(s) from the liquid nitrogen Dewar and thaw at room temperature (C2C12 cells) or within an incubator at $37^{\circ} \mathrm{C}$ (primary cells).

3. For $\mathrm{C} 2 \mathrm{C} 12$ cells, seed cell suspension onto the pregelatinized $\mathrm{T} 75$ flask(s) and add $10 \mathrm{ml}$ of growth medium per flask. Gently agitate to ensure even distribution across the culture flask

surface and place in an incubator $\left(37^{\circ} \mathrm{C}\right)$ to allow cells to grow to $80 \%$ confluency over the ensuing days (typically $72 \mathrm{~h}$ ).

4. For primary cells, transfer cell suspension into a sterile $15 \mathrm{ml}$ tube and centrifuge at $200 \mathrm{x} \mathrm{g}$ for $10 \mathrm{~min}$.

5. Remove supernatant and resuspend cell suspension and $6 \mathrm{ml}$ of growth medium onto the pregelatinized T25 flask.

6. Once $80 \%$ confluent, resuspend primary cells onto a T75 flask and passage until the desired cell population is attained (see Note 21).

\subsection{Preparation of 3-D Culture Dishes}

1. Sylgard coat dishes according to the manufacturer's instructions. Briefly, on a covered surface, add curing agent to elastomer and stir to ensure a consistent silicone solution (see Note 4). Using a syringe (without needle), add $1.5 \mathrm{ml}$ of silicone to each dish. Allow coated dishes to cure for approximately $24 \mathrm{~h}$. Once cured, replace lids and store for at least 1 week prior to using for muscle cultures (see Note 24).

2. Prepare 4 x $0.15 \mathrm{~mm}$ minutien pins and 2 × $6 \mathrm{~mm}$ silk sutures per dish (see Notes 5 and 6 ).

3. Using a "fine point" sharpie and ruler, mark the $6,12,18,24,30 \mathrm{~mm}$ points across the center of each dish (see Note 25). 
A
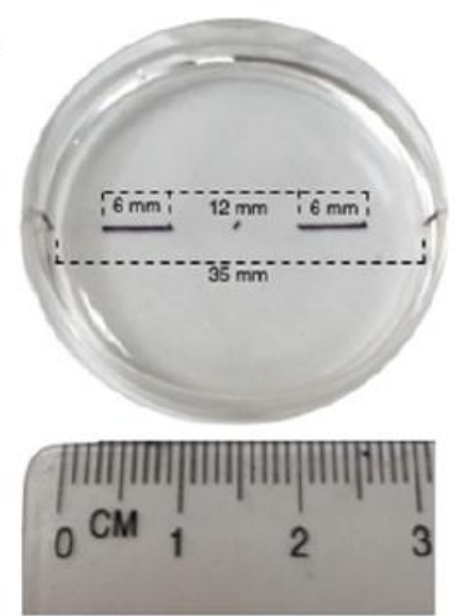

C

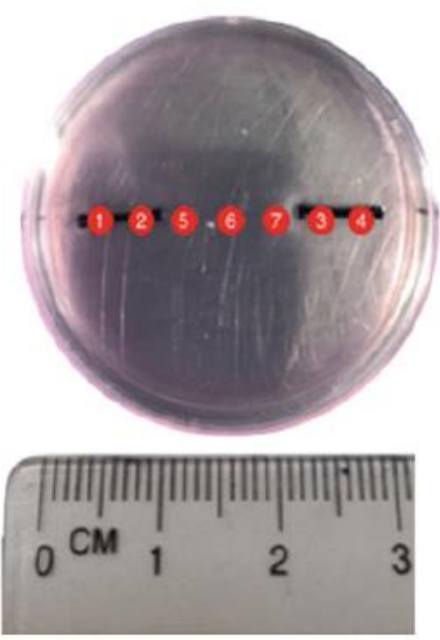

B

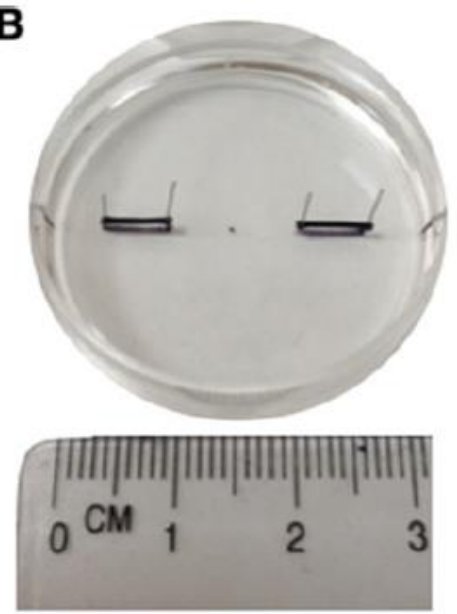

D

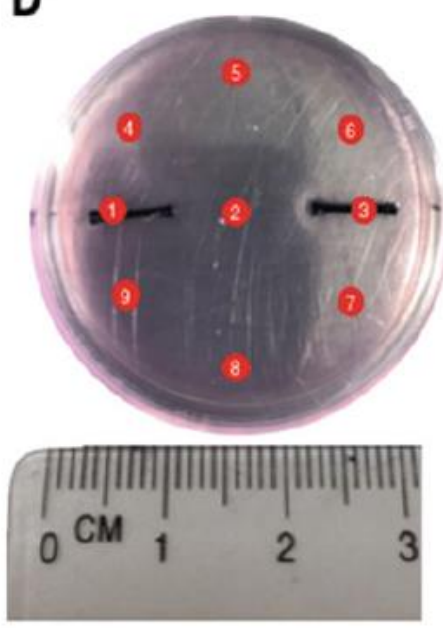

Fig. 2 Depicts (A) marked sylgard coated 3-D culture dish with (B) silk sutures pinned in place. (C) Depicts thrombin solution placement to ensure sutures are saturated and (D) indicates pipetting fibrinogen dropwise prior to gentle agitation to ensure even distribution across the cell culture dish surface

Mark a line between the 6-12 and 24-30 mm points to ensure accurate silk suture alignment when pinning in place (Fig. 2).

4. Align silk sutures between $6-12$ and $24-30 \mathrm{~mm}$ points and pin in place ensuring a $12 \mathrm{~mm}$ gap in-between (Fig. 2).

5. Following preparation of 3-D culture dishes, thoroughly spray the inside of the lid and culture dish with $70 \%$ immersed methylated spirit (IMS)/ethanol and leave in a Class 2 cell culture hood/BSC under UV to sterilise and air-dry overnight (see Note 26). 
A

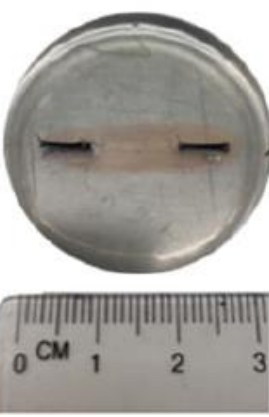

D

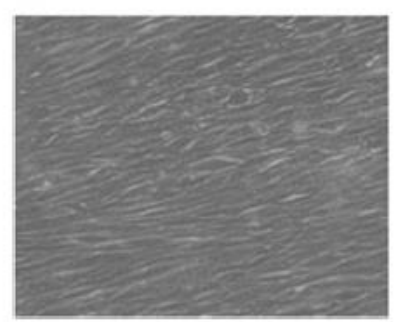

B

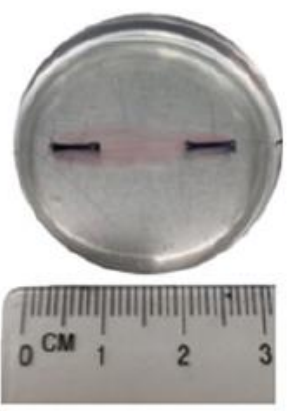

E

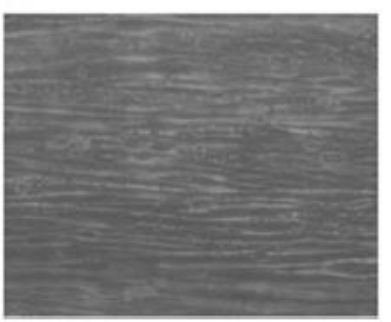

C

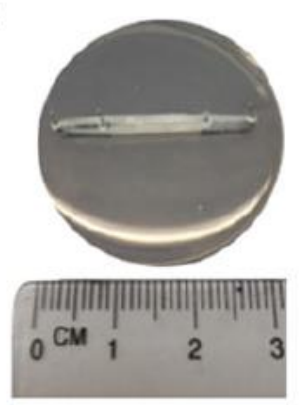

$\mathbf{F}$

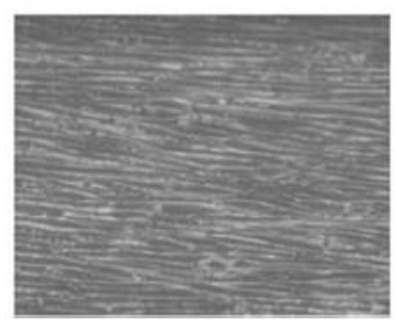

Fig. 3 Macroscopic images of C2C12 3-D fibrin muscle constructs at (a) 3 days (b) 7 days and (c) 14 days in culture. $(\mathbf{d}-\mathbf{f})$ depict microscopic bright field images $(10 \times$ magnification) at 3,7 and 14 days, respectively

\subsection{Preparation and Maintenance of Fibrin Skeletal Muscle Constructs}

1. Before proceeding, ensure all 3-D culture dishes, relevant reagents, medium and cells are prepared as described above. For each fibrin muscle construct, thaw $50 \mu \mathrm{l} / \mathrm{ml}$ thrombin, $8 \mu 1 / \mathrm{ml}$ aprotinin (see Note 27), $20 \mu \mathrm{l} / \mathrm{ml}$ genipin (see Note 13) and $200 \mu \mathrm{l}$ fibrinogen at room temperature while cell suspension is incubating at $37^{\circ} \mathrm{C}$. Growth medium for thrombin solution should also reach room temperature prior to using.

2. Add thrombin, aprotinin and genipin (see Note 13) to growth medium to ensure $500 \mu \mathrm{l}$ of solution per gel (see Notes 27 and 28).

3. Coat dishes with $500 \mu \mathrm{l}$ of thrombin/aprotinin/genipin gel solution (see Note 29) (Fig. 2).

4. Add $200 \mu \mathrm{l}$ of fibrinogen dropwise around the culture dishes and agitate gently to ensure even distribution with the thrombin solution (Fig. 2).

5. Allow the fibrin gel to polymerize at room temperature for 10 mins prior to incubating at $37^{\circ} \mathrm{C}$ for $1 \mathrm{~h}$.

6. Following polymerization, seed $2 \mathrm{ml}$ cell suspension per dish consisting of 100,000-200,000 cells $/ \mathrm{ml}$ (primary [10]) or 50,000-90,000 cells/ml (C2C12) in growth medium (see Note 30). 

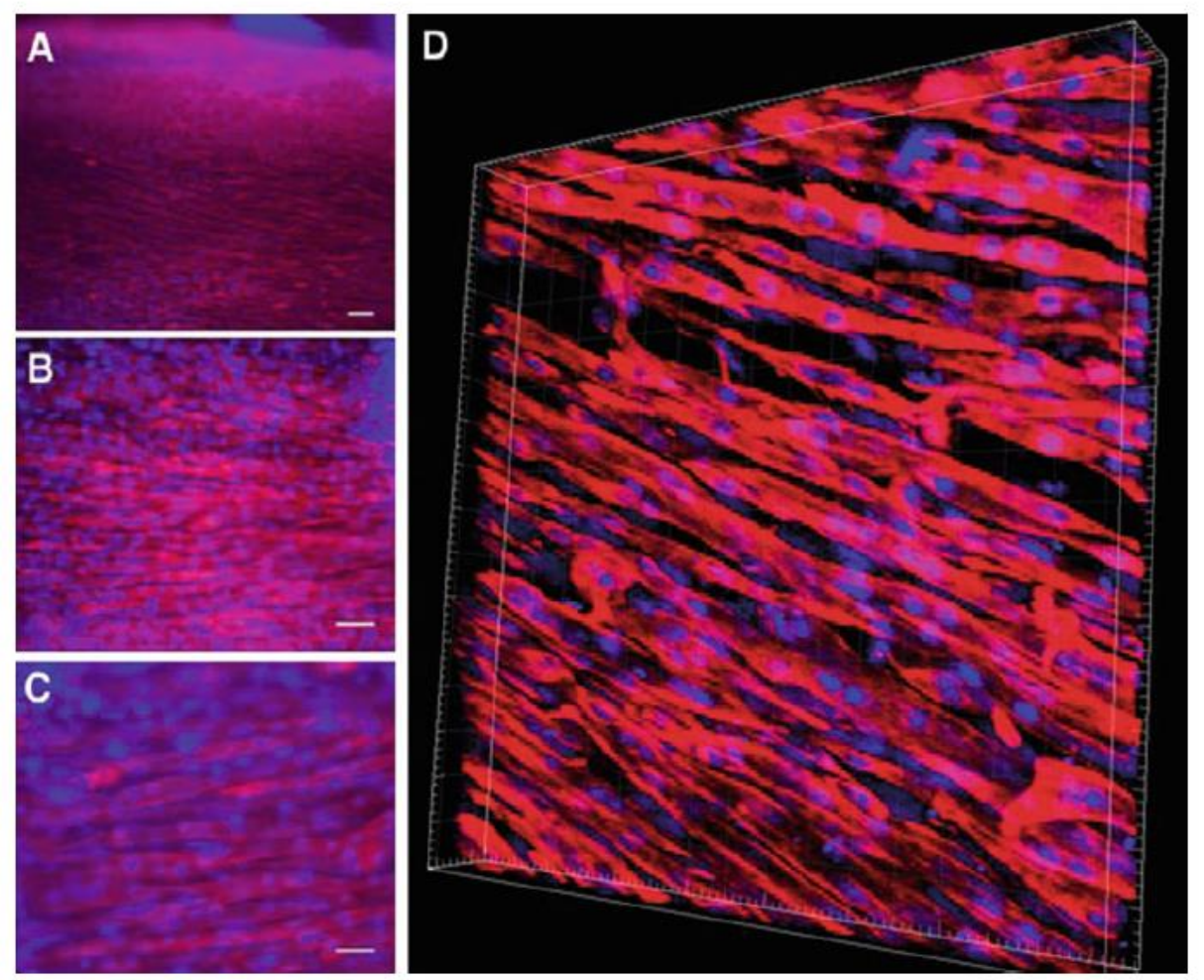

Fig. 4 Immuno-stained microscopic (Nikon, Eclipse Ti-S) images of C2C12 3-D fibrin constructs at (a) $10 \times$ (scale bar $=50 \mu \mathrm{m})($ b) $20 \times($ scale bar $=20 \mu \mathrm{m})$ and (c) $40 \times($ scale bar $=20 \mu \mathrm{m})$ magnification. (d) Z-stack animated confocal (Olympus, IX83) microscopic image $(40 \times$ magnification). Constructs were stained for desmin (red) and nuclei (blue)

7. Gently agitate culture dishes and place in the incubator at $37^{\circ} \mathrm{C}$. Growth medium should be changed every 48 h until cells reach $\sim 90 \%$ confluency (Fig. 3).

8. Once approximately $90 \%$ confluent, aspirate remaining growth medium and $3 \times$ PBS wash (see Note 31 ). 9. Transfer to $2 \mathrm{ml}$ of preheated $\left(37^{\circ} \mathrm{C}\right.$ ) differentiation medium and incubate at $37^{\circ} \mathrm{C}$ for $48 \mathrm{~h}$ (see Notes 31 and 32).

10. Remove differentiation media and wash cells as in step 8 (see Note 31), transfer to $2 \mathrm{ml}$ of maintenance medium, and incubate at $37^{\circ} \mathrm{C}$ (see Note 33). Be sure to wash cells as in step 8 (see Note 31) and top up or change maintenance medium (see Note 34) for 14 days to allow constructs to mature (Figs. 3

and 4). The gel will contract from the edge of the dish and roll into a cylindrical-like muscle whereby multinucleated myotubes will form in aligned and parallel fashion in line with the direction of the sutures (Figs. 3 and 4).

\subsection{From the Culture Dish to the Bioreactor}

1. Preheat maintenance medium to $37^{\circ} \mathrm{C}$.

2. Remove bioreactor chamber(s) and parts (screws, clamps, etc.) from the autoclave bag and assemble the bottom the clamps.

3. Manually adjust the distance between the medial edge of each clamp to ensure a $12 \mathrm{~mm}$ gap (see Note 35) and tighten to prevent any unwanted change in resting length.

4. Using sterile angled tweezers (see Note 1), remove pins from the culture dish and transfer the muscle construct (leaving sutures in if possible) from the cell culture well/dish to the bioreactor chamber(s) (see Notes 16, 35-37).

5. Avoiding any stretching or twisting of the muscle construct, clamp the medial end of each suture embedded within either side of the construct (see Notes 36 and 37).

6. Submerge the clamped construct(s) with $20 \mathrm{ml}$ of maintenance medium by pipetting into the bioreactor chamber(s) (see Notes 31 and 38).

7. The muscle construct is now ready to undergo electrical and/or mechanical stimulation. 


\subsection{Bioreactor Setup}

1. Ensure enough free bench space to position all bioreactor equipment (Fig. 5).

2. Connect electrical stimulation and control modules to the mains power supply (ensure the mains is switched off until all other equipment is connected).

3. Connect laptop/desktop, mechanical stimulation box, and electrical stimulation output box to the control module.

4. Connect neutral, anode (+ve), and cathode (-ve) from the electrical stimulation module to the electrical stimulation output box.

5. Connect the anode/cathode splitter to the electrical stimulation output box.

6. Feed electrodes through bioreactor chamber(s) and connect to the anode/cathode splitter (see Notes 39 and 40) (Fig. 6).

7. Attach bioreactor chamber(s) to mechanical stimulation unit, ensuring the resting length $(12 \mathrm{~mm})$ is maintained (see Note 41).

8. Once assembled, loosen the tension of the chamber (s) mechanical arm to permit movement when initiating the mechanical stretch regime.

\subsection{Electrical and Mechanical Stimulation}

1. Open the "Ebers TC-3 with Electrical Stimulation" software from the desktop/application menu.

2. From the "port settings" dropdown menu, ensure the control module is connected to the device containing the controlling software in order to proceed ("COM3").

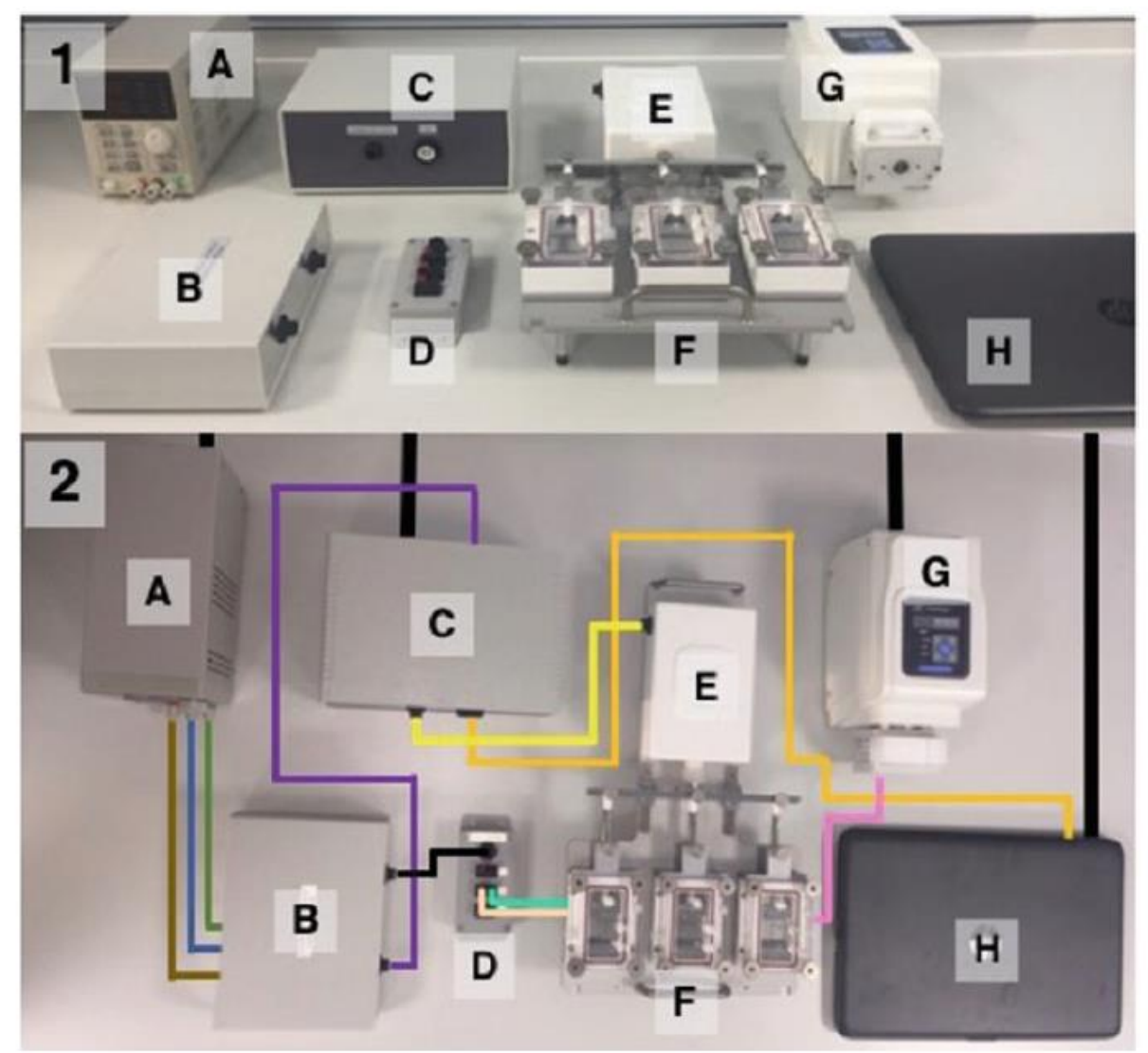

Fig. 5 (1) Frontal and (2) bird's-eye view of the TC-3 Bioreactor System, (EBERS Medical Technology, ESP) including the (A) electrical stimulation module, (B) electrical stimulation output box, (C) control module, (D) electrode anode/cathode splitter, (E) bioreactor mechanical stimulation box, (F) bioreactor 3-D cell culture chamber, (G) peristaltic pump/perfusion box, (H) laptop and controlling software. Image and figure legend adapted from [28] with permission from Wiley 
3. Click "start" from the "manual mode" panel until the mechanical stretch arm reaches the desired resting length.

4. Click "stop" and "Set to 0" to confirm the starting length. It isat this point you may loosen the tension of he mechanical stretch arm as the chamber should be securely attached to the mechanical stimulation unit (see Note 41).

5. From the "program mode" panel, select the desired "Run (seconds; s)" and "Pause (seconds; s)" duration, the "ramp mode" and whether you would like the regime to "cycle"

(Fig. 7).

6. Navigate to the "record number" to alter "velocity mode" and "frequency mode" settings (Fig. 7).

7. From the "velocity mode" function, the desired stretch limit/ "travel" (millimeters; mm), direction (backward/forward), "minimal/target speed" (millimeters per second; $\mathrm{mm} / \mathrm{s}$ ) and "acceleration/brake ramp" (millimeters per second squared; mm/s2) can be altered (Fig. 7; see Note 42).

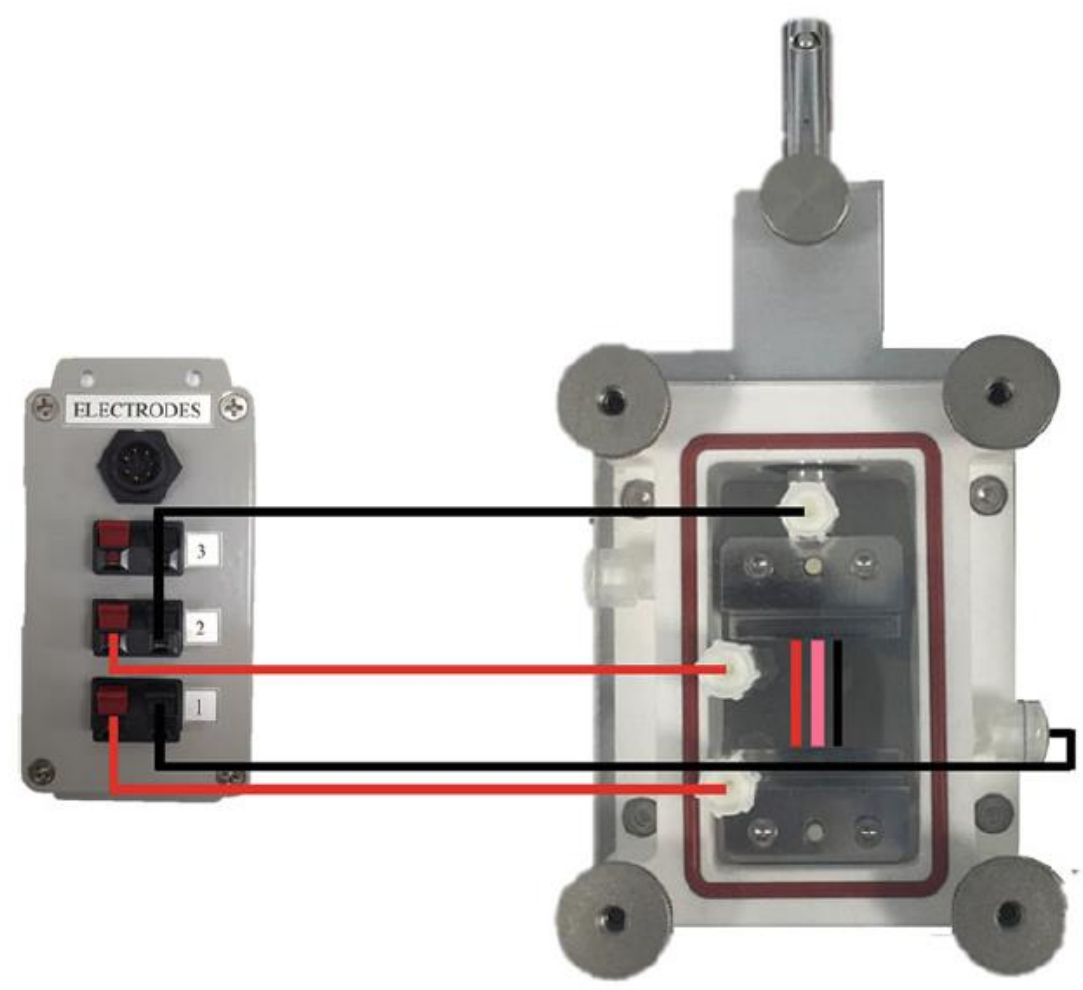

Fig. 6 Electrode placement for electrical stimulation. Anode (red) and cathode (black) pathways to the electrical anode/cathode splitter using platinum or stainless steel wire running parallel to the clamped muscle construct (pink) 
A

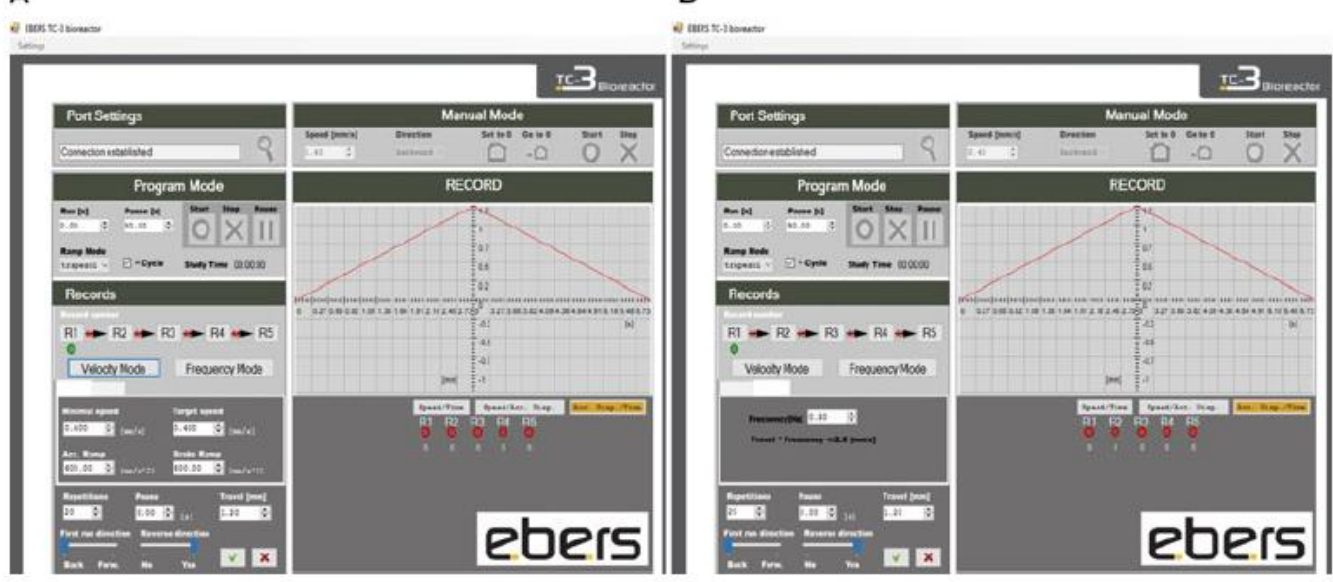

Fig. 7 Ebers TC-3 Software. Mechanical stretch navigation menu for adjusting (a) velocity and (b) frequency mode settings

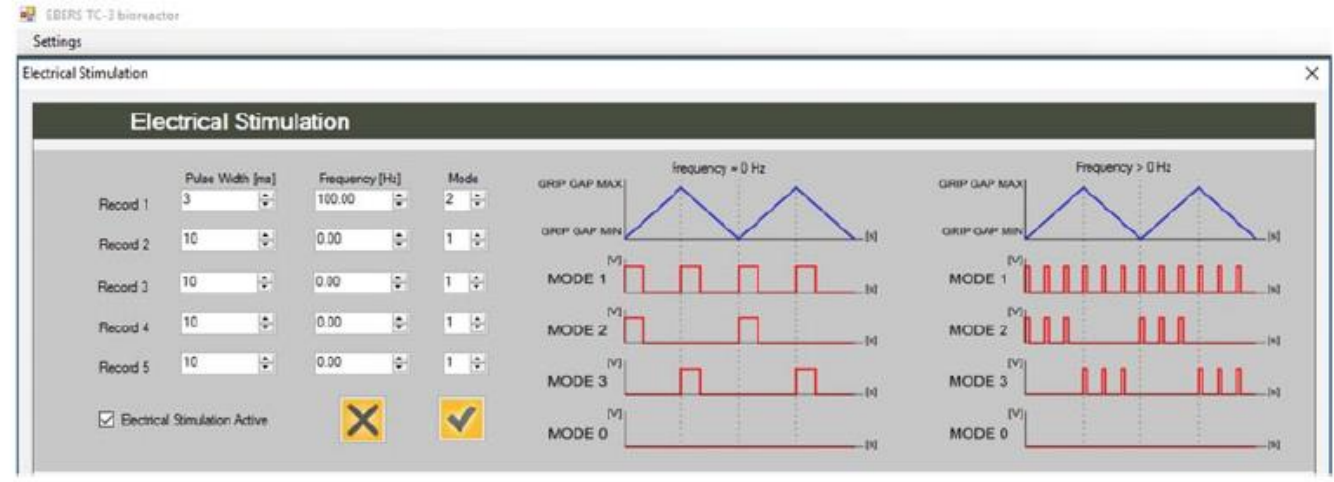

Fig. 8 Ebers TC-3 Software. Electrical stimulation navigation menu for adjusting pulse width (ms), frequency $(\mathrm{Hz})$ and "MODE"

8. From the "frequency mode" function, the stretch frequency (hertz; Hz) can be altered. Click the "green tick" to confirm the desired mechanical stretch regime (see Note 42).

9. To adjust the electrical stimulation protocol, navigate to the "electrical stimulation" function from the "settings" dropdown menu. Here, single impulses or pulse trains can be applied during the "forward" (when the muscle returns to its' resting length; MODE 3), "backward" (when the muscle is lengthening to reach the desired stretch limit; MODE 2), forward and backward movements combined (MODE 1) or at "rest" (MODE 0) (see Notes 43 and 44; Fig. 8).

10. Set the desired pulse width (milliseconds; ms), frequency (Hertz; Hz), amplitude (voltage; V), pulse train (seconds; s) and "MODE" number (see Note 44).

11. Confirm the desired electrical stimulatory parameters via clicking the "Electrical Stimulation Active" option followed by the tick option on screen (Fig. 8).

12. Following cessation of the mechanical and/or electrical stimulatory regime, click "stop" and lock the bioreactor chamber (s) stretch arm.

13. Ensure the electrical stimulation module is switched off at the mains and disconnect the electrodes from the anode/cathode splitter.

14. Place the chamber(s) in the incubator at $37^{\circ} \mathrm{C}$ and incubate for the desired post-exercise period.

15. Remove chamber(s) from the incubator and place in a sterile Class 2 cell culture hood.

16. Remove the clamps using sterile tools (see Note 1) and transfer the stimulated fibrin muscle using sterile tweezers (see Notes 1 and 16) for your desired sample preparation. For RNA/DNA/ protein isolation we recommend homogenization in tubes containing MagNA Lyser Green Beads (submerged in the relevant lysis buffer) in a MagNA tissue Lyser for 6,000 rpm x $40 \mathrm{~s}$ (with $5 \mathrm{~min}$ rest on ice in between each cycle), and repeated 3 times. 
17. Ensure all equipment is switched off and all working areas are thoroughly cleaned.

18. Ensure to package bioreactor chamber(s), relevant parts (clamps and screws) and tools and sterilise for future use (see Note 1).

\section{Notes}

1. Sterilize via autoclaving (e.g., $122^{\circ} \mathrm{C}$ for $30 \mathrm{~min}$ ).

2. hiFBS and hiNBCS are purchased from South America (EU approved) and New Zealand. It is also important to use serum from the same origin due to disparities in hormonal milieu (hiFBS from US vs. EU origin) which may alter the engineered muscle phenotype [29].

3. Use gelatin from porcine skin A (and not B) given that gelatin B may negatively affect skeletal muscle cell growth.

4. Pour curing agent into Sylgard, mixing thoroughly from side-to-side as well as top-to-bottom to guarantee curing when coating the culture dishes (it is normal for small bubbles to appear when mixing). It is also important to syringe (without a needle) Sylgard onto the culture dishes as soon as possible followed by agitation to ensure even distribution.

5. Cut pins in half to enable replacement of culture dish lids. There is no required length of pins, as long as the lid can be replaced.

6. Cut silk suture thread to $6 \mathrm{~mm}$ lengths. Using a disposable scalpel is preferable as using scissors causes greater incidence of fraying.

7. Dissolve $1 \mathrm{~g}$ of fibrinogen in $50 \mathrm{ml}$ of Ham's F12-K medium to ensure enough reagent for approximately 250 fibrin gels given $200 \mu \mathrm{l}$ is required per fibrin muscle construct.

8. It is suggested to filter fibrinogen through a $0.22 \mu \mathrm{m}$ large vacuum filter as fibrinogen blocks the filter membranes when using $0.22 \mu \mathrm{m}$ syringe filters.

9. Do not freeze-thaw.

10. Thrombin can be purchased as $1 \mathrm{KU}$ containing $27 \mathrm{mg}$. Therefore, there are approximately 37 units per mg, totaling 999 units. Each $1 \mathrm{KU}$ should therefore provide enough reagent for 200 fibrin gels at $10 \mathrm{U} / \mathrm{ml}$ when diluted with growth medium given $25 \mu \mathrm{l}$ is required per fibrin muscle construct.

11. 6-Aminocaproic acid inhibits plasmin activity and subsequent fibrinolysis [30] induced by high levels of plasminogen by $\mathrm{C} 2 \mathrm{C} 12$ myoblast cells. Overall use and specific concentration should therefore depend on the occurrence and rate of fibrinolysis since plasminogen is also required for muscle cell differentiation $[31,32]$. It is suggested to culture without at first and then add $0.5 \%$ (final conc. $0.25 \mathrm{mg} / \mathrm{ml}$ ) to growth medium, $1 \%$ (final conc. $0.5 \mathrm{mg} / \mathrm{ml}$ ) to differentiation medium and $1 \%$ (final conc. $0.5 \mathrm{mg} / \mathrm{ml}$ ) to maintenance medium if the fibrin matrix is degrading. If these concentrations do not reduce fibrinolysis, attempt to increase the concentrations to those described herein.

12. The amino acid L-proline and cofactor L-ascorbic acid (vitamin C) may encourage the production of ECM proteins in primary cultures, such as collagen and improve engineered musculoskeletal mechanics [33]. Use should therefore depend on the occurrence and rate of fibrin degradation. They are not always required if the gels are not degrading.

13. Genipin slows fibrin matrix degradation rates however at the expense of reduced force production [18]. Genipin also autofluoresces, negatively affecting any fluorescent/confocal microscopy performed and subsequent morphological analysis [18]. Therefore, its use should be determined by the most important dependant variables of interest within individual experiments.

14. Depending on the desired experimental measures, perhaps refrain from using streptomycin given the resultant alterations in force production and muscle phenotype following electrical stimulation $[34,35]$.

15. The TC-3 bioreactor system (Ebers Medical Technology, ESP) described herein is a commercially available, easy-to-use bioreactor system that permits simultaneous mechanical and electrical stimulation according to software amendments (see Note 41). Although the protocol described herein is specific to using the TC-3 bioreactor system, the principles remain the same if using customized/other commercially available bioreactor systems that enable similar stimulatory regimes.

16. Holding both sets of angled tweezers in one hand for simultaneous opening and closing permits greater control when transferring the muscle construct from the culture wells into the bioreactor chamber(s).

17. Local anesthetic, particularly bupivacaine are considered to induce myotoxic effects [36] which may be attributable to increased intracellular calcium release with simultaneous inhibition of calcium reuptake into the sarcoplasmic reticulumn [37]. Inclusion and/or selection of local anesthetic should therefore be determined by the most important dependent variables of interest within individual experiments. 
18. A needle biopsy yields $20-30 \mathrm{mg}$ whereas a conchotome biopsycan yield $100-250 \mathrm{mg}$ of skeletal muscle tissue. If conducting a needle biopsy, you may require multiple passes. Therefore, use the sterile wound dressing kit to wipe and clear the biopsy area before proceeding with the next pass of a needle biopsy in order to reduce risk of infection.

19. Hand pipette as opposed to vacuum aspirate to ensure greater control.

20. If the enzymatic digestion technique is successful, there are typically a low number of cells that grow from the remaining explanted tissue over the ensuing days. If so, dispose of the remaining explanted tissue according to the relevant legislations, (e.g. in the UK, the Human Tissue Act, 2004).

21. Primary human skeletal muscle derived cells start to senesce after several passages. Some may senesce even after 5-8 passages in-vitro depending on the age of the donor. This is because their drive in-vivo is to undergo a few rounds of proliferation only before fusing to fibers to repair/regenerate the fiber. Cells will still fuse once senescent, but this may affect their initial growth when expansion/proliferation is required for the initial stage of making a self-assembling fibrin bioengineered muscle. Therefore, this should be a consideration when determining participant number, expected cell retrieval and the number of fibrin bioengineered constructs required to suit the experimental design of the study.

22. Homogenize suspension via pipetting up and down prior to resuspending.

23. Pipette DMSO down the side of the specimen container/tube in a dropwise manner while simultaneously swirling/mixing the solution in the tube.

24. It is best to allow sylgard spillages on bench surfaces to completely dry before removing using a gel scraper (or similar) and wiping.

25. Usually, there are lined marks on either side of the dish indicating the center line. Therefore, holding a ruler in line with these points when marking ensures accurate suture alignment when pinning in place.

26. Plates may only require 30 mins of sterilization to remove visible ethanol; however, it is likely that the sutures will stilln be saturated in ethanol. Therefore, air drying overnight is preferable.

27. Concentration of the protease inhibitor aprotinin should be optimized according to the rate of fibrinolysis (degradation of fibrin). Since the $\mathrm{C} 2 \mathrm{C} 12$ myoblast cell line produces high levels of plasminogen and matrix metalloproteinases, we suggest adding $8 \mu \mathrm{l} / \mathrm{ml}$ of aprotinin to the thrombin solution. However, when using human skeletal muscle derived cells that contain a proportion of fibroblasts within the myoblast population that lay down additional matrix, we suggest reducing concentrations to $4 \mu \mathrm{l} / \mathrm{ml}$.

28. Prepare sufficient excess thrombin gel solution for an additional gel (every 10 fibrin gels) to compensate for any potential minor pipetting error or loss of residual solution from the outside of pipette tips.

29. To ensure consistency between gels, pipette the thrombin solution along the sutures (outside to inside) and then across the center to join both sutures. Next, tilt the dish horizontally along the line of the sutures. Once the solution makes contact with both edges of the dish, rotate the dish in a circular motion so the solution now covers the entire edge of the dish. Resting the base of the dish on the culture hood surface, gently agitate to ensure even distribution across the dish surface (Fig. 2). It is important any bubbles appearing during this process are carefully removed, popping with a sterile syringe needle if required.

30. It is essential that cells are spread evenly across the dish to ensure consistent growth and attachment of the cells in a uniform fashion. We recommend adding $2 \mathrm{ml}$ of cell suspension at 200,000 cells/ml for primary human gels [10] and 90,000 cells $/ \mathrm{ml}$ for $\mathrm{C} 2 \mathrm{C} 12$ gels.

31. Avoid pipetting PBS or media directly onto the fibrin gel in attempt to reduce cell disruption and potential tearing of the gel.

32. Gels are changed to lower serum to enable fusion/differentiation of single cells to form multinucleated myotubes.

33. Cells are switched from low serum (2\% HS) differentiation medium to higher serum (7\% hiFBS/hiNBCS) maintenance medium to reduce likelihood of gel degradation. Cells will continue to fuse and myotubes mature when under tension within the bioengineered system while in the presence of $7 \%$ serum in the medium.

34. Cells must be provided with sufficient nutrients to promote maturation and reduce the risk of gel degradation. Maintenance medium is changed following 2 x PBS washes every $48 \mathrm{~h}$. However, $0.5 \mathrm{ml}$ of fresh medium is added on days where medium is not changed to help maintain any secreted factors by the cells that may promote differentiation and myotube hypertrophy.

35. Loosen the tension on the bioreactor chamber(s) arm to enable adjustment. Using a ruler, ensure a 12 $\mathrm{mm}$ gap between the medial edges of both clamps and tighten the bioreactor chamber(s) arm to avoid any unwanted changes in resting length.

36. Using the Ebers TC-3 bioreactor (Ebers Medical Technology, ESP), it is possible to mechanically load x 3 muscle constructs per chamber, totaling 9 muscle constructs per single regime (across 3 x chambers). 
However, the electrical stimulation setup described herein permits stimulation of just one muscle construct per chamber due to the space required for electrode wiring.

37. If the sutures are removed from the muscle construct during the transferring process, it is important to ensure the amount of muscle clamped at either side is the same. Ideally all other constructs in the same experiment would then be treated in this way, or that gel removed from the experiment.

38. If stimulating engineered muscle constructs in the absence or presence of specific nutrients (e.g. amino acids) according to the desired experimental measures, immersing constructs in Krebs Ringer HEPES (KRH) buffer rather than maintenance medium may be preferable. For Krebs-Ringer-HEPES (KRH) buffer at $\mathrm{pH}$ 7.4 (10x): $10 \mathrm{mM}$ HEPES, $138 \mathrm{mM} \mathrm{NaCI}, 4.7 \mathrm{mM} \mathrm{KCl}, 1.25 \mathrm{mM} \mathrm{CaCl}$, $1.25 \mathrm{mM} \mathrm{MgSO}, 5 \mathrm{mM}$ Glucose and $5 \mathrm{mg} / \mathrm{ml}$ bovine serum albumin (BSA) diluted in $\mathrm{dH}_{2} 0$.

39. Use rounded plyers to bend electrodes and feed through the culture chamber(s) to ensure electrodes run parallel with the muscle construct (Fig. 6).

40. For health and safety reasons, purchase electrode wire surrounded with plastic coating or self-coat with only the portion assembled through the bioreactor chamber(s) being exposed.

41. Attach the bottom of the bioreactor chamber(s) to the mechanical stretch unit, ensuring each chamber is slightly tilted (approximately $45^{\circ}$ ). Manually adjust the mechanical stretch unit arm onscreen using the "start" function until the mechanical arm attached to the bioreactor chamber(s) clicks in place. Click "stop" and "set to 0 " to set the starting position.

42. Example Mechanical Stretch Regimes: Cyclic stretch ( 1 cycle 3 sets x 5 reps, each set interspersed with $\sim 30 \mathrm{~s}$ rest). Undertake these cycles with 5\% strain for 2 days, $10 \%$ strain for 2 days, and $15 \%$ strain for 4 days in an attempt to model progressive overload that has been demonstrated to evoke myotube hypertrophy [23]. Static stretch, where the construct is stretched to $10 \%$ quickly (e.g., $0.4 \mathrm{~mm} / \mathrm{s}$ resulting in $1.2 \mathrm{~mm}$ stretch of a $1.2 \mathrm{~cm}$ fibrin muscle after $3 \mathrm{~s}$ ) and held at $10 \%$ stretch for $1 \mathrm{~h}$ to provide a model that would be most similar to synergistic ablation $[22,38]$. Continuous ramp load at $0.35 \mathrm{~mm} / \mathrm{h}$, which is the same rate at which stretch stimulates in-vivo bone elongation during development [9]. 10\% intermittent stretch $\mathrm{x}(1$ interval, 4 sets $\times 10$ reps at $0.4 \mathrm{~mm} / \mathrm{s}$ during stretch and return to resting length, resulting in $1.2 \mathrm{~mm}$ stretch of a $1.2 \mathrm{~cm}$ fibrin muscle in $3 \mathrm{~s}$ and a return to resting length after $3 \mathrm{~s}$, with each set interspersed with $90 \mathrm{~s}$ rest). Each interval is separated by $3.5 \mathrm{~min}$ rest and repeated, e.g., 3-5 times in an attempt to replicate a similar number of repetitions performed during a typical in-vivo bout of resistance type exercise that evokes hypertrophy (e.g., 4 sets x 10 reps x $3-5$ exercises per muscle group).

43. Initially, only mechanical stretch or electrical stimulation could be applied at a given time. Specifically, a single pulse could only be applied when the desired stretch limit was attained or when at the initial resting position. Therefore, we liaised with the manufacturer (Ebers Medical Technology, ESP) regarding potential software (TC-3) modifications that would enable simultaneous electrical and mechanical stimulation to the 3D fibrin muscle constructs Ebers proceeded with the requested amendments, with the TC-3 bioreactor now permitting the application of pulse trains (rather than a single pulse at maximal stretch or at resting length) for continuous synchronized impulses during the whole mechanical cycle (Fig. 8). Furthermore, the bioreactor system now also permits the use of an external electrical stimulator for synchronization of mechanical stretch and electrical stimulation, providing a fail-safe if the internal stimulation box was to stop working but also enabling the use of more powerful or in-house stimulators in the future for higher sustained/repetitive pulse frequencies.

44. Example Electrical Stimulation Regimes: Chronic low-frequency stimulation (CLFS) to evoke slow fiber formation (pulse frequency. $10 \mathrm{~Hz}$; contraction duration, 60-600 s, adjusting rest intervals to ensure $60 \%$ active time, changing medium every $24 \mathrm{~h}$ and continue for a 14 day period) [39]. Higher frequency stimulatory regime to more closely mimic a more forceful contraction (pulse frequency. $100 \mathrm{~Hz}$; amplitude. $2.5 \mathrm{~V} / \mathrm{mm} ; 4 \times 0.1 \mathrm{~ms}$ pulses delivered in a $400 \mathrm{~ms}$ pulse train followed by $3.6 \mathrm{~s}$ recovery) and repeated the desired number of times to mimic, e.g., resistance exercise in-vivo [5].

\section{References}

1. Brevet A, Pinto E, Peacock J, Stockdale FE (1976) Myosin synthesis increased by electrical stimulation of skeletal muscle cell cultures. Science 193(4258):1152-1154

2. Wehrle U, Dusterhoft S, Pette D (1994)

Effects of chronic electrical stimulation on myosin heavy chain expression in satellite cell cultures derived from rat muscles of different fiber-type composition. Differentiation 58 (1):37-46. https://doi.org/10.1046/j.14320436.1994.5810037.x

3. Vandenburgh H, Kaufman S (1979) In vitro

model for stretch-induced hypertrophy of skeletal muscle. Science 203(4377):265-268

4. Baar K, Torgan CE, Kraus WE, Esser K (2000)

Autocrine phosphorylation of p70(S6k) in 
response to acute stretch in myotubes. Mol Cell Biol Res Commun 4(2):76-80. https:// doi.org/10.1006/mcbr.2000.0257

5. Donnelly K, Khodabukus A, Philp A, Deldicque L, Dennis RG, Baar K (2010) A novel bioreactor for stimulating skeletal muscle in vitro. Tissue Eng Part C Methods 16 (4):711-718. https://doi.org/10.1089/ten. TEC.2009.0125

6. Nedachi T, Fujita H, Kanzaki M (2008) Contractile $\mathrm{C} 2 \mathrm{C} 12$ myotube model for studying exercise-inducible responses in skeletal muscle. Am J Physiol Endocrinol Metab 295(5): E1191-E1204. https://doi.org/10.1152/ ajpendo. 90280.2008

7. Nikolic N, Bakke SS, Kase ET, Rudberg I, Flo

Halle I, Rustan AC, Thoresen GH, Aas V (2012) Electrical pulse stimulation of cultured human skeletal muscle cells as an in vitro model of exercise. PLoS One 7(3):e33203. https:// doi.org/10.1371/journal.pone.0033203

8. Vandenburgh HH (1988) A computerized mechanical cell stimulator for tissue culture: effects on skeletal muscle organogenesis. In Vitro Cell Dev Biol 24(7):609-619

9. Vandenburgh HH, Karlisch P (1989) Longitudinal growth of skeletal myotubes in vitro in a new horizontal mechanical cell stimulator. In Vitro Cell Dev Biol 25(7):607-616 10. Martin NR, Passey SL, Player DJ, Khodabukus A, Ferguson RA, Sharples AP, Mudera V, Baar K, Lewis MP (2013) Factors affecting the structure and maturation of human tissue engineered skeletal muscle. Biomaterials 34(23):5759-5765. https://doi.

org/10.1016/j.biomaterials.2013.04.002

11. Sharples AP, Player DJ, Martin NR, Mudera V, Stewart CE, Lewis MP (2012) Modelling in vivo skeletal muscle ageing in vitro using three-dimensional bioengineered constructs. Aging Cell 11(6):986-995. https://doi.org/ 10.1111/j.1474-9726.2012.00869.x

12. Dennis RG, Kosnik PE 2nd (2000) Excitability and isometric contractile properties of mammalian skeletal muscle constructs engineered in vitro. In Vitro Cell Dev Biol Anim 36 (5):327-335. https://doi.org/10.1290/ 1071-2690(2000)036<0327:eaicpo>2.0. co;2

13. Dennis RG, Kosnik PE 2nd, Gilbert ME, Faulkner JA (2001) Excitability and contractility of skeletal muscle engineered from primary cultures and cell lines. Am J Physiol Cell Physiol 280(2):C288-C295

14. Huang YC, Dennis RG, Baar K (2006) Cultured slow vs. fast skeletal muscle cells differ in physiology and responsiveness to stimulation. Am J Physiol Cell Physiol 291(1):

C11-C17. https://doi.org/10.1152/ajpcell. 00366.2005

15. Huang YC, Dennis RG, Larkin L, Baar K (2005) Rapid formation of functional muscle in vitro using fibrin gels. J Appl Physiol 98 (2):706-713. https://doi.org/10.1152/ japplphysiol.00273.2004

16. Martin NR, Passey SL, Player DJ, Mudera V, Baar K, Greensmith L, Lewis MP (2015) Neuromuscular junction formation in tissueengineered skeletal muscle augments contractile function and improves cytoskeletal organization. Tissue Eng Part A 21

(19-20):2595-2604. https://doi.org/10. 1089/ten.TEA.2015.0146

17. Khodabukus A, Baar K (2012) Defined electrical stimulation emphasizing excitability for the development and testing of engineered skeletal muscle. Tissue Eng Part C Methods 18 (5):349-357. https://doi.org/10.1089/ten. TEC.2011.0364

18. Khodabukus A, Baar K (2009) Regulating fibrinolysis to engineer skeletal muscle from the $\mathrm{C} 2 \mathrm{C} 12$ cell line. Tissue Eng Part C Methods 15(3):501-511. https://doi.org/10. 1089/ten.TEC.2008.0286

19. Cheng CS, Ran L, Bursac N, Kraus WE, Truskey GA (2016) Cell density and joint microRNA-133a and microRNA-696 inhibition enhance differentiation and contractile function of engineered human skeletal muscle tissues. Tissue Eng Part A 22(7-8):573-583. https://doi.org/10.1089/ten.TEA.2015. 0359

20. Shahini A, Choudhury D, Asmani M, Zhao R, Lei P, Andreadis ST (2017) NANOG restores the impaired myogenic differentiation potential of skeletal myoblasts after multiple population doublings. Stem Cell Res 26:55-66. https://doi.org/10.1016/j.scr.2017.11.018 21. Khodabukus A, Baar K (2015) Contractile and metabolic properties of engineered skeletal muscle derived from slow and fast phenotype mouse muscle. J Cell Physiol 230

(8):1750-1757. https://doi.org/10.1002/ jcp. 24848

22. Player DJ, Martin NR, Passey SL, Sharples AP, Mudera V, Lewis MP (2014) Acute mechanical overload increases IGF-I and MMP-9 mRNA in 3D tissue-engineered skeletal muscle. Biotechnol Lett 36(5):1113-1124. https://doi. org/10.1007/s10529-014-1464-y 23. Powell CA, Smiley BL, Mills J, Vandenburgh HH (2002) Mechanical stimulation improves tissue-engineered human skeletal muscle. Am J Physiol Cell Physiol 283(5):C1557-C1565. https://doi.org/10.1152/ajpcell.00595.2001 24. Yaffe D, Saxel O (1977) Serial passaging and differentiation of myogenic cells isolated from dystrophic mouse muscle. Nature 270 (5639):725-727

25. Blau HM, Pavlath GK, Hardeman EC, Chiu CP, Silberstein L, Webster SG, Miller SC, Webster $C$ (1985) Plasticity of the differentiated state. Science 230(4727):758-766

26. Patel HP, Syddall HE, Martin HJ, Stewart CE, Cooper C, Sayer AA (2010) Hertfordshire sarcopenia study: design and methods. BMC Geriatr 10:43. https://doi.org/10.1186/1471-

2318-10-43

27. Crown AL, He XL, Holly JM, Lightman SL, Stewart CE (2000) Characterisation of the IGF system in a primary adult human skeletal muscle cell model, and comparison of the effects of insulin and IGF-I on protein metabolism. J Endocrinol 167(3):403-415 
28. Kasper AM, Turner DC, Martin NRW, Sharples AP (2018) Mimicking exercise in threedimensional bioengineered skeletal muscle to investigate cellular and molecular mechanisms of physiological adaptation. J Cell Physiol 233 (3):1985-1998. https://doi.org/10.1002/ jcp. 25840

29. Khodabukus A, Baar K (2014) The effect of serum origin on tissue engineered skeletal muscle function. J Cell Biochem 115

(12):2198-2207. https://doi.org/10.1002/ jcb. 24938

30. Adelman B, Rizk A, Hanners E (1988) Plasminogen interactions with platelets in plasma.

Blood 72(5):1530-1535

31. Lopez-Alemany R, Suelves M, Munoz-

Canoves P (2003) Plasmin generation dependent on alpha-enolase-type plasminogen receptor is required for myogenesis. Thromb Haemost 90(4):724-733. https://doi.org/ 10.1160/th03-04-0291

32. Suelves M, Lopez-Alemany R, Lluis F, Aniorte G, Serrano E, Parra M, Carmeliet P, Munoz-Canoves P (2002) Plasmin activity is required for myogenesis in vitro and skeletal muscle regeneration in vivo. Blood 99

(8):2835-2844

33. Paxton JZ, Grover LM, Baar K (2010) Engineering an in vitro model of a functional ligament from bone to bone. Tissue Eng Part A 16 (11):3515-3525. https://doi.org/10.1089/ ten.TEA.2010.0039

34. Khodabukus A, Baar K (2015) Glucose concentration and streptomycin alter in vitro muscle function and metabolism. J Cell Physiol 230 (6):1226-1234. https://doi.org/10.1002/ jcp. 24857

35. Khodabukus A, Baar K (2015) Streptomycin decreases the functional shift to a slow phenotype induced by electrical stimulation in engineered muscle. Tissue Eng Part A 21

(5-6):1003-1012. https://doi.org/10.1089/ ten.TEA.2014.0462

36. Zink W, Sinner B, Zausig Y, Graf BM (2007)

Myotoxicity of local anaesthetics: experimental myth or clinical truth? Anaesthesist 56

(2):118-127. https://doi.org/10.1007/ s00101-006-1121-5

37. Zink W, Graf BM, Sinner B, Martin E, Fink RH, Kunst G (2002) Differential effects of bupivacaine on intracellular $\mathrm{Ca}$ 2. regulation: potential mechanisms of its myotoxicity. Anesthesiology 97(3):710-716

38. Goldberg AL (1967) Work-induced growth of skeletal muscle in normal and hypophysectomized rats. Am J Phys 213(5):1193-1198.

https://doi.org/10.1152/ajplegacy.1967.

213.5.1193

39. Khodabukus A, Baehr LM, Bodine SC, Baar K (2015) Role of contraction duration in inducing fast-to-slow contractile and metabolic protein and functional changes in engineered muscle. J Cell Physiol 230(10):2489-2497. https://doi.org/10.1002/jcp.24985 